ORIGINAL RESEARCH

\title{
A Novel Cooling Method and Comparison of Active Rewarming of Mildly Hypothermic Subjects
}

\author{
Mark L. Christensen, DO; Grant S. Lipman, MD; Dennis A. Grahn, PhD; Kate M. Shea, MD; Joseph Einhorn, MD; \\ H. Craig Heller, PhD \\ From the Department of Emergency Medicine, Stanford University School of Medicine (Drs Christensen, Lipman, and Shea); Department of \\ Biology, Stanford University (Drs Grahn and Heller); and Stanford - Kaiser Emergency Medicine Residency, Stanford, CA (Dr Einhorn).
}

\begin{abstract}
Objective.-To compare the effectiveness of arteriovenous anastomosis (AVA) vs heated intravenous fluid (IVF) rewarming in hypothermic subjects. Additionally, we sought to develop a novel method of hypothermia induction.

Methods.-Eight subjects underwent 3 cooling trials each to a core temperature of $34.8 \pm 0.6$ (32.7 to $36.3^{\circ} \mathrm{C}$ [mean $\pm \mathrm{SD}$ with range]) by $14^{\circ} \mathrm{C}$ water immersion for 30 minutes, followed by walking on a treadmill for 5 minutes. Core temperatures $(\Delta$ tes $)$ and rates of cooling $\left({ }^{\circ} \mathrm{C} / \mathrm{h}\right)$ were measured. Participants were then rewarmed by 1) control: shivering only in a sleeping bag; 2) IVF: shivering in sleeping bag and infusion of $2 \mathrm{~L}$ normal saline warmed to $42^{\circ} \mathrm{C}$ at $77 \mathrm{~mL} / \mathrm{min}$; and 3) AVA: shivering in sleeping bag and circulation of $45^{\circ} \mathrm{C}$ warmed fluid through neoprene pads affixed to the palms and soles of the feet.

Results. - Cold water immersion resulted in a decrease of $0.5 \pm 0.5^{\circ} \mathrm{C} \Delta$ tes and $1 \pm 0.3^{\circ} \mathrm{C}$ with exercise $(P<.01)$; with an immersion cooling rate of $0.9 \pm 0.8^{\circ} \mathrm{C} / \mathrm{h}$ vs $12.6 \pm 3.2^{\circ} \mathrm{C} / \mathrm{h}$ with exercise $(P<.001)$. Temperature nadir reached $35.0 \pm 0.5^{\circ} \mathrm{C}$. There were no significant differences in rewarming rates between the 3 conditions (shivering: $1.3 \pm 0.7^{\circ} \mathrm{C} / \mathrm{h}, R^{2}=0.683 ;$ IVF $1.3 \pm 0.7^{\circ} \mathrm{C} / \mathrm{h}$, $R^{2}=0.863$; and AVA $\left.1.4 \pm 0.6^{\circ} \mathrm{C} / \mathrm{h}, R^{2}=0.853 ; P=.58\right)$. Shivering inhibition was greater with AVA but was not significantly different $(P=.07)$.

Conclusions.-This study developed a novel and efficient model of hypothermia induction through exercise-induced convective afterdrop. Although there was not a clear benefit in either of the 2 active rewarming methods, AVA rewarming showed a nonsignificant trend toward greater shivering inhibition, which may be optimized by an improved interface.
\end{abstract}

Keywords: hypothermia, rewarming, glabrous skin, arteriovenous anastomosis, afterdrop

\section{Introduction}

Accidental hypothermia, an involuntary drop in core body temperature $\leq 35^{\circ} \mathrm{C}\left(95^{\circ} \mathrm{F}\right),{ }^{1,2}$ is a potentially lethal condition that accounts for approximately 600 deaths in the United States each year and commonly complicates trauma or illness as a secondary condition. ${ }^{3}$ There is a 7

Corresponding author: Mark L Christensen, DO, Stanford University School of Medicine, Stanford, CA, 291 Campus Drive, Stanford, CA 94305; e-mail: mm81mm81@gmail.com.

Presented at the Word Congress of Wilderness Medicine, Telluride, CO, August 2, 2016, and the SAEM Annual Meeting, New Orleans, LA, May 10-13, 2016.

Submitted for publication August, 2016.

Accepted for publication February, 2017 to $23 \%$ mortality rate associated with mild to moderate hypothermia on emergency room and intensive care unit admission that doubles the odds of mortality compared to normothermic patients. ${ }^{2,4}$ Hypothermia often occurs far from definitive medical care, where invasive rewarming techniques are unavailable, necessitating external rewarming methods that have been found to have rates similar to shivering alone ${ }^{5-10}$ because the increase in skin temperature from exogenous heat suppresses the peripheral shivering stimulus and subsequent heat production. $^{7,11}$ However, shivering suppression has the theoretical advantage of increased comfort, decreased physiologic strain, and conservation of energy stores. ${ }^{11}$

Peripheral vasoconstriction is the body's initial response to cooling. ${ }^{12}$ This vasomotor reaction limits 
the transfer of heat from the body's skin to the body's core. It is well recognized that exercise after cold water immersion causes a drop in temperature (afterdrop) as warm central blood perfuses cold extremities and this muscle-driven cold peripheral blood redistributes or convectively transfers cold back to the core. This convective cooling has been found to be 3 times greater than passive cooling ${ }^{13}$; however, this phenomenon has not been tested for hypothermia induction in translational research.

Immersion of arms and legs in 42 to $45^{\circ} \mathrm{C}$ water have resulted in rewarming rates 2 to 3 times faster than the commonly recommended external rewarming modalities. $^{14,15}$ This is likely due to warming of the glabrous (nonhairy) skin regions that cover the soles of the feet and palms of the hands. These areas contain retia venosa, specialized densely packed subcutaneous arteriovenous anastomoses (AVA) that are under both local vasomotor and thermoregulatory control and have significant effects on thermoregulation. ${ }^{16,17}$ The AVA have the capacity for very high blood flow and bypass cold arterioles, capillaries, and peripheral insulating tissues to deliver blood directly to the retia venosa. The retia venosa can radiate heat if cooling is needed or rewarm large volumes of venous blood that go directly to the core. When AVA structures vasodilate, they have been shown to facilitate heat exchange more than 5 times that of nonglabrous skin during exercise. ${ }^{18}$ Hypothermic rewarming by warm water immersion, to date, has limited field applications due to logistical constraints and theoretical risk of inducing cardiovascular collapse. ${ }^{19}$ A recommended prehospital rewarming treatment used by search and rescue teams, emergency medical services, and the military is administration of warmed intravenous fluids (IVF). ${ }^{3,19-23}$ Prior to administration, IVF should be warmed to 38 to $42^{\circ} \mathrm{C},{ }^{1-3}$ as $21^{\circ} \mathrm{C}$ (room temperature) IVF decreases normothermic core temperatures by $0.3^{\circ} \mathrm{C} / \mathrm{L} \cdot{ }^{24} \mathrm{~A}$ liter of $40^{\circ} \mathrm{C}$ IVF provides $8 \mathrm{kcal}$ of heat directly into circulating normothermic blood. ${ }^{4,25,26}$ While studies have examined the perioperative prevention of inadvertent hypothermia, the physiologic effects of warmed IVF in hypothermic individuals has not been studied.

The purpose of this study was to develop and test a novel methodology of heat distribution to induce hypothermia and then to compare active rewarming techniques vs spontaneous rewarming in mildly hypothermic participants. Our hypotheses were that use of convective cooling would be faster than immersive conductive cooling and the AVA rewarming would result in the most rapid rate of rewarming.

\section{Methods}

\section{PARTICIPANTS}

Eight healthy volunteers participated in this prospective randomized crossover trial. They were recruited via email listservs and word-of-mouth. They completed a Physical Activity Readiness Questionnaire to ensure the absence of any cardiopulmonary risk factors. No participants were excluded from the study. Written informed consent was obtained from each subject.

Anthropometric data including age, weight, height, and measurements of skinfold thickness at 4 sites (biceps, triceps, subscapularis, and suprailiac) was collected for body fat analysis (calculated from the Durnin/Womersley caliper method) prior to first cooling trial. Subjects were instructed to abstain from alcohol, medications, and any vigorous physical activity for a 24-hour period prior to each immersion trial. The study was approved by the Stanford University School of Medicine Institutional Review Board (NCT02339103).

\section{FACILITIES AND EQUIPMENT}

The trials were conducted in a $2.4 \times 3.3 \times 2.4 \mathrm{~m}$ temperature-controlled environmental chamber. The trial conditions were held at an ambient temperature of $10^{\circ} \mathrm{C}$ and relative humidity of 20 to $35 \%$. The treadmills (model SC7000, SCIFIT, Tulsa, OK) were housed in the experimental chamber.

Esophageal temperature (Tes) and heart rate were monitored throughout each trial. Tes was measured with a commercially available general-purpose thermocouple probe (Mon-a-therm No. 503-0028, Mallinckrodt Medical Inc., St. Louis, MO). These probes were self-inserted by the subjects through the nose to the base of the probe at a depth of 38 to $39 \mathrm{~cm}$ and held in place by a loop of surgical tape (Transpore, 3M Corporation, Saint Paul, $\mathrm{MN})$ adhered to the skin adjacent to the naris. The probes were connected to a laptop-based thermocouple transducer/data collection system (GEC instruments, Gainesville, FL), which recorded temperature data at 1 -second intervals. Heart rate monitors/data loggers (model S810, Polar Electro Oy, Kempele, Finland) were used to record and collect heart rate data at 5-second intervals. At the end of each trial, temperature data were downloaded to a central computer and transferred to a spreadsheet (Microsoft Excel) for subsequent analysis. Shivering was quantified at 5-minute intervals by the Bedside Shivering Assessment Scale, a validated quantification method for shivering. $^{27,28}$ 


\section{COOLING PROTOCOL}

Subjects served as their own controls for comparative evaluation of 3 different rewarming modalities. The order of the trials followed the control (shivering alone) arm, with subjects randomized to successive rewarming trials by a coin toss and trials separated by at least 48 hours. After instrumentation and initial data acquisition, the subjects sat in a $10^{\circ} \mathrm{C}$ temperature-controlled chamber for 10 minutes of baseline data collection. They were then submerged to the level of the sternal notch in a bath of circulating $14^{\circ} \mathrm{C}$ water. All participants wore bathing suits. The subjects remained in the bath for 30 minutes with the water temperature held constant at $14^{\circ} \mathrm{C}$ for the duration of the trial. After 30 minutes had elapsed, the subject exited the water, towel dried, then walked at 8 $\mathrm{kph}$ on the treadmill for 5 minutes, still in the cold room.

\section{REWARMING METHODS}

Following cooling, subjects were placed in a sleeping bag $\left(+20^{\circ} \mathrm{F}\right.$ Goose Down, REI, Kent, WA) zippered around the head and donned a balaclava to simulate standard prehospital hypothermia field insulation treatments. $^{29,30}$ They then sat on a webbed chair for a minimum of 60 minutes, or until Tes reached $37^{\circ} \mathrm{C}$. For the SO (control arm), no exogenous heat source was used, and the subject was placed in the sleeping bag and rewarmed spontaneously through endogenous shivering thermogenesis.

For the glabrous skin rewarming (AVA), neoprene mittens and slippers with incorporated perfusion pads circulated with hot water were placed on both hands and feet to abut the respective glabrous skin regions before being placed in the sleeping bag. The water perfusion pads were supplied by a standard clinical circulatingwater, patient-temperature management system (eg, CSZ Blanketrol III, Cincinnati Sub-Zero, Cincinnati, OH) that circulated $42^{\circ} \mathrm{C}$ water, a temperature that is below the burn threshold for glabrous skin. Study subjects kept perfusion pads in place for the duration of the recovery period. For the heated IVF arm, subjects had an $18 \mathrm{~g}$ angiocatheter (Model 38170, Becton, Dickinson and Company, Franklin Lakes, NJ) placed in one randomly chosen antecubital fossa and covered with a tegaderm. Prior to delivery, $1 \mathrm{~L}$ bags of $0.9 \%$ normal saline (model NDC 0409-7983-09, Hospira Inc., Lake Forest, IL) that had been housed in the environmental chamber under study conditions for 24 hours were immersed in circulating $45^{\circ} \mathrm{C}$ water for 2 hours. They were then placed in a $50 \times 40 \times 0.12 \mathrm{~cm}\left(19 " \times 16^{\prime \prime} \times 0.5\right.$ " $)$ neoprene pocket cut to enable folding into a $30 \times 15 \times 5 \mathrm{~cm}(12$ " $\times 6 " \times 2$ ") rectangle with overlapping sides. $^{31}$ The warmed IVF were then suspended $150 \mathrm{~cm}$ above the angiocatheter tip and infused through uninsulated $280 \mathrm{~cm}$ standard IV tubing (Primary Symbiq Set, Hospira, Inc, Lake Forest, IL). All IVF was run "wide open," which was measured with a graduated cylinder and a stopwatch as approximately $77 \mathrm{~mL} / \mathrm{min}$ ( $\approx 1 \mathrm{~L} / 13$ minutes). Two liters of fluid prepared in this method were infused in total. Research has shown that infusion of IVF warmed to $46.3 \pm 1.7^{\circ} \mathrm{C}$ and administered in this manner under the same environmental conditions delivered IV fluids at a temperature of $39.7 \pm 0.7^{\circ} \mathrm{C}^{31}$

After each rewarming trial was completed, the subjects were transferred to a warm ambient temperature room. After the last trial, each subject completed a short questionnaire comparing the 3 rewarming methods and provided feedback regarding comfort and preference.

\section{DATA ANALYSIS}

The Tes data were sampled at 1-second intervals and the heart rate data at 5-second intervals. Esophageal temperature and heart rate vs time graphs of the raw data were generated for each trial. The Tes vs time plots were screened for swallowing artifact using computer software, and artifacts were removed from the data set. The data sets were reduced by sampling data at 30 -second intervals. Cleaned data from the resting/recovery portion of the trials were selected and plotted as a function of time. The data analyzer was blinded to the intervention arm.

Individual trial recovery Tes data were grouped according to treatment and further reduced by sampling the data by a single-point measure at 5-minute intervals; group mean and SDs were calculated at each 5-minute time point. The treatment group mean data were plotted against time. The rates of temperature changes (Tes vs time) were calculated for each trial using a linear regression analysis (Microsoft Excel). The results of the linear regression analyses were sorted by subject and treatment and analyzed by 2 -factor analysis of variance with no replication and no post hoc $\mathrm{t}$ tests $(P<.05$ were considered statistically significant).

\section{POWER ANALYSIS}

Sample size was calculated according to data from previous studies with similar rewarming protocols. ${ }^{7,13,32}$ To achieve $80 \%$ power $(\alpha=0.05,2$-tailed test $)$, assuming intervention of the experimental method was a SD greater than the traditional method, the minimal sample size to detect a statistically significant difference was 6 . 


\section{Results}

Eight subjects ( 2 female) were enrolled. Individual characteristics are presented in the Table. Age ranged from 20 to 64 years (mean $\pm \mathrm{SD}, 32.3 \pm 13.8$ ). Body mass index and body fat were $23.7 \pm 2.8 \mathrm{~kg} / \mathrm{m}^{2}$ and $23.8 \pm 8.5 \%$, respectively.

Thirty minutes of cold water immersion resulted in a $0.5 \pm 0.5^{\circ} \mathrm{C}$ decrease in $\Delta \mathrm{Tes}$ (rate of change of Tes $=$ $0.9 \pm 0.8^{\circ} \mathrm{C} / \mathrm{h}$ ). After the 5-minute treadmill walk, the core temperature dropped $1 \pm 0.3^{\circ} \mathrm{C} \Delta$ Tes (rate of change of Tes $=12.6 \pm 3 \cdot 2^{\circ} \mathrm{C} / \mathrm{h}$ ). Temperature decreases during the postimmersion exercise phase were significantly greater than the temperature decreases during the water immersion phase both in magnitude $(P<.01)$ and rate $(P<.001)$ (Figure 1). Core temperatures reached a nadir of $34.8 \pm 0.6\left(32.7\right.$ to $\left.36.3^{\circ} \mathrm{C}\right)$. There were no significant differences in rewarming rates between the 3 conditions (shivering: $1.3 \pm 0.7^{\circ} \mathrm{C} / \mathrm{h}, R^{2}=0.683$; IVF: $1.3 \pm 0.7^{\circ} \mathrm{C} / \mathrm{h}$, $R^{2}=0.863$; and AVA: $1.4 \pm 0.6^{\circ} \mathrm{C} / \mathrm{h}, R^{2}=0.853 ; P=$ .58) (Figure 2).

After undergoing all immersion trials, 7 (88\%) participants felt that glabrous skin AVA rewarming was the most comfortable treatment method, and $6(75 \%)$ participants felt that IV fluid rewarming was most uncomfortable. Total shivering was assessed by adding scores (0-3) taken at 5-minute intervals during the rewarming period. Total shivering was highest during the control arm of shivering alone. Although not statistically significant in either of the active rewarming methods, a trend was observed toward maximum shivering suppression in the AVA arm $(P=.07)$ (Figure 3).

\section{Discussion}

The use of afterdrop phenomena to equalize the distribution of heat in mildly hypothermic individuals caused a precipitous drop in core temperature that induced cooling 12 times faster than the rate observed during immersion cooling. We reached target cold temperatures

Table. Participant Characteristics

\begin{tabular}{lllll}
\hline Participant & Age $(y)$ & Sex & BMI $\left(\mathrm{kg} / \mathrm{m}^{2}\right)$ & Body fat $(\%)$ \\
\hline 1 & 33 & F & 19.8 & 26.6 \\
2 & 64 & F & 25.4 & 42.1 \\
3 & 28 & M & 23.5 & 19.5 \\
4 & 28 & M & 23.6 & 18.1 \\
5 & 21 & M & 23.7 & 17.0 \\
6 & 31 & M & 28.6 & 27.9 \\
7 & 20 & M & 20.2 & 17.8 \\
8 & 33 & M & 25.1 & 20.8 \\
Mean \pm SD & $32.3 \pm 13.8$ & N/A & $23.7 \pm 2.8$ & $23.8 \pm 8.5$ \\
& & & & \\
\hline
\end{tabular}

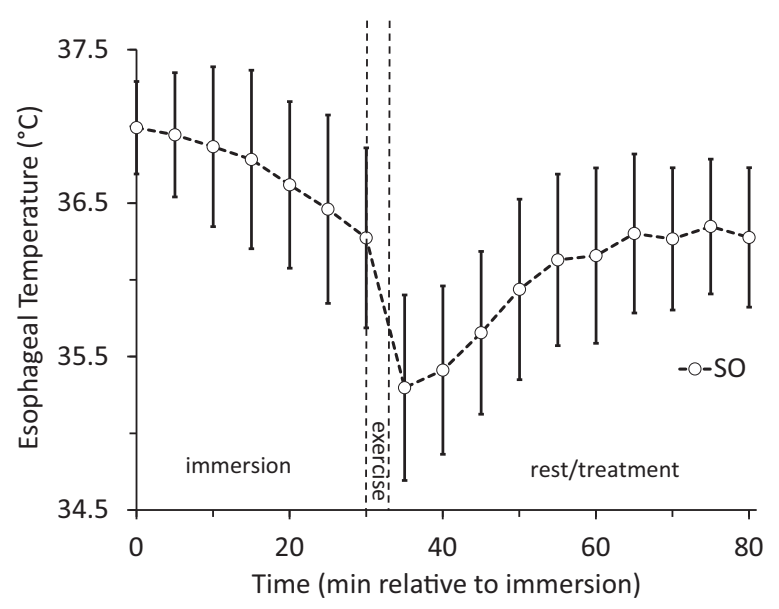

Figure 1. Esophageal temperature (Tes) (mean \pm SD) during 30 minutes of cold water immersion, 5 minutes of postimmersion exercise, and 45 minutes of resting recovery with warming by shivering only (SO).

in less than half of the 60- to 90-minute immersion in $8^{\circ} \mathrm{C}$ water needed in prior studies. ${ }^{5,7,33,34}$ Minimizing both the temperature of the water, as well as the total time of immersion, likely limited participant discomfort, and this methodology may assist with future hypothermia investigations.

Translational crossover studies of hypothermia are confounded by the fact that the treatment used to induce hypothermia creates a large disequilibrium in the distribution of heat in the body. The body responds to cold with redistribution of blood flow that keeps heat in the core of the body (approximately 10\% of body mass) ${ }^{35}$

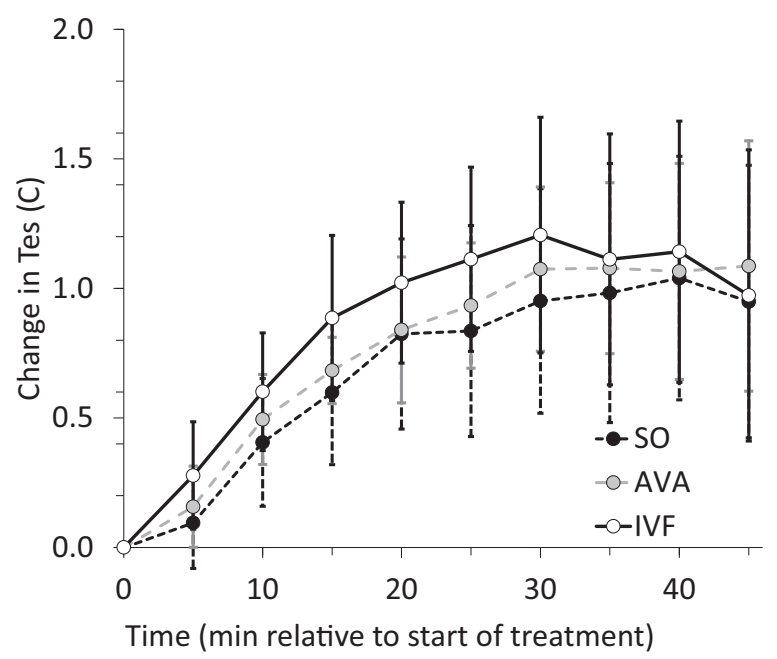

Figure 2. Effect of 3 warming treatments on changes in esophageal temperatures (Tes) (mean $\pm \mathrm{SD}$ ) over time during recovery from mild hypothermia. SO, shivering only; AVA, warm water circulating pads applied to the palms of the hands and soles of the feet; IVF, $2 \mathrm{~L}$ of $42^{\circ} \mathrm{C}$ intravenous fluid infusion. 


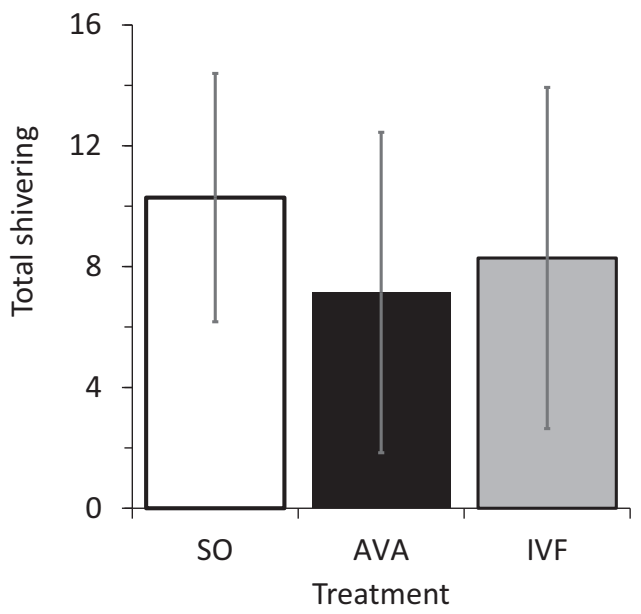

Figure 3. Effect of 3 warming treatments on total shivering by Bedside Shivering Assessment Scale (mean \pm SD) during 45 minutes of recovery from mild hypothermia. SO, shivering only; AVA, warm water circulating pads applied to the palms of the hands and soles of the feet; IVF, $2 \mathrm{~L}$ of $42^{\circ} \mathrm{C}$ intravenous fluid infusion.

while letting peripheral tissues cool. As a result, the measured core temperature, whether it be Tes, tympanic, or rectal, is not an accurate reflection of the total change in the heat content of the body. By using exercise to increase blood flow to the peripheral tissues and redistribute this cold blood back to the core, the afterdrop in core temperature may be a more accurate reflection of the total amount of heat lost by the body during cold exposure.

We found the rate of core rewarming was not significantly different between active external rewarming through glabrous skin with AVA, active internal rewarming through IVF, and passive rewarming by shivering alone. All observed rewarming rates followed predictable patterns. ${ }^{7,10}$ The application of heated circulating water to the glabrous AVA skin surface of the palms and soles was not found to provide the same rewarming rates of 6 to $10^{\circ} \mathrm{C} / \mathrm{h}$ seen in studies that immersed the entire forearms and legs. ${ }^{14,15}$ Also, the smaller rewarming rate achieved through glabrous skin seen in this study is in contrast to the rapid rewarming benefit measured in studies of recovery of hypothermic subjects by palmar warming with the addition of subatmospheric pressure, even when applied to a single hand. ${ }^{17,18}$ We have 2 hypothetical explanations. First, the subatmospheric vasodilation in prior studies may have made a large difference in hypothermic and tightly vasoconstricted individuals; second, the very low core temperature induced by afterdrop could create a central stimulus to close the AVA that is then difficult to overcome through induction of AVA opening with local application of heat.
This was the first controlled study to examine the effect of warmed IVF in hypothermia. Intravenous fluids are often indicated in hypothermia resuscitation because cold stress induces diuresis through stimulation of peripheral vasoconstriction, impaired renal-tubule concentrations, and diminished antidiuretic hormone release. ${ }^{36}$ Treatment by fluid boluses is recommended to prevent cooling of the warmed fluids as well as rapid repletion of the vascular space. ${ }^{19}$ Ambulances often have ambient temperature fluids, ${ }^{37}$ and, in cold environments, traditional fluid delivery systems can induce a significant decrease in core temperature during transport. ${ }^{20}$ This study demonstrates that warmed fluids insulated in a neoprene sleeve do not decrease core temperatures, providing evidence to support empiric recommendations to deliver intravenous fluids warmed to $42^{\circ} \mathrm{C}$ to hypothermic individuals. It is not surprising, however, that a warming benefit was not seen, because $2 \mathrm{~L}$ represents approximately $4 \%$ of total body water; adding this little amount of heat to a large cold reservoir should not make an appreciable clinical difference.

Shivering is triggered by peripheral receptors in the skin, organs, and central nervous system, with greater effect on temperature via central receptors. ${ }^{38-40}$ As ambient temperature drops, cooling skin sends signals to the hypothalamus, which in turn triggers a shivering response. The resultant heat production helps to maintain thermal homeostasis in the body. A mildly hypothermic, vigorously shivering person can increase heat production to 5 to 6 times the basal metabolic rate, rewarming at a rate of 1 to $2^{\circ} \mathrm{C} / \mathrm{h}$. $^{7}$ Subjects in the glabrous skin warming AVA arm showed a nonsignificant trend toward greater shivering inhibition during the rewarming period. While not statistically significant, the observed difference could be due to the fact that glabrous skin warming is a more efficient mode of rewarming, thus requiring less additional endogenous heat generation.

Although application of external heat is not always necessary in a mildly hypothermic person, it may still be beneficial in conserving energy stores and decreasing physiologic strain. ${ }^{3,19}$ Furthermore, in the mildly hypothermic patient who may be wet or have depleted energy stores, making it more difficult to warm by shivering alone, active rewarming may prevent physiologic decompensation either in the field or en route to a hospital. Core temperatures below $32^{\circ} \mathrm{C}$ are associated with an altered sensorium, limiting the ability to provide caloric thermogenesis; below $30^{\circ} \mathrm{C}$, extinction of the shivering response necessitates external heat application for rewarming. ${ }^{41}$ Comparisons of rewarming modalities have been traditionally run with mildly hypothermic 
healthy volunteers, and results are accepted as generalizable to more severe forms of hypothermia. ${ }^{42,43}$

\section{LIMITATIONS}

Intravenous fluids were delivered with neoprene pouch, flow rate, and environmental conditions identical to those tested and described in a prior study, ${ }^{31}$ although the liter bag was warmed in circulating water rather than by flameless ration heaters. Because the internal temperature was identical, it is unlikely there was any difference in delivery temperature, although this was not directly measured in our study.

Due to safety concerns, and in an effort to develop a novel cooling method, there was no inhibition of shivering in our subjects. The effectiveness of the shivering response may have overshadowed subtler temperature changes that might have been observed if shivering had been suppressed. The shivering assessment scale used in this study is a subjective measure that limits its precision. Future studies could use electromyography, skin temperature measurement, oxygen uptake, or other more objective data to better quantify shivering responses.

Studies of mildly hypothermic people yield results that are limited in generalizability to more severely hypothermic patients. Due to potential risks, it is both unsafe and unethical to induce these temperatures in healthy subjects. Past studies examining mild hypothermia and rewarming rates have similarly accepted their results as generalizable to more severe forms of hypothermia. The rate of cooling was observed for a short duration because of the achievement of the desired cooling effect, and although the rates may not be indicative of longerduration trends, extrapolation of cooling trends was similar to prior cold water immersion studies. ${ }^{14,33}$ Healthy volunteers in this study achieved a core temperature at the upper end of the widely accepted definition of mild hypothermia. ${ }^{1,2,14,19}$ Future studies could modify the cooling protocol to achieve more consistent temperatures of $<35^{\circ} \mathrm{C}$ and to cool participants for longer durations to determine whether the observed rapid rates of change of afterdrop cooling are consistent.

Characteristics including age, body mass index, and body fat percentage have been shown to affect cooling and rewarming rates. ${ }^{44}$ The participants in this study showed variability in these characteristics, although comparison of their cooling and rewarming rates did not show any significant outliers. While the variability in heterogonous characteristics may limit the ability to apply these findings to the general population, these characteristics are likely generalizable to victims of hypothermia.
The glabrous skin interface used in this study was another potential limitation. The warm water perfusion pads (insulated by neoprene) were intended to minimize external heat loss and maximize conductive heat transference. Future trials would benefit from design modification intended to provide greater insulation and increased surface contact between glabrous skin and water perfusion pads. The addition of subatmospheric pressure might be necessary to overcome the AVA vasoconstriction induced by the hypothermic state and result in greater heat transfer into the retia venosa.

\section{Conclusions}

This study developed a novel method of rapidly equalizing body heat distribution to induce hypothermia that may be advantageous for future translational cold studies. Although there was no clear benefit in rewarming rates with either of the 2 active rewarming methods, glabrous skin rewarming had the greatest subjective comfort and showed a trend toward greater shivering inhibition, which may be optimized by an improved interface.

Author Contributions: Study concept and design (MLC, GSL, DAG, HCH); acquisition of the data (MLC, KMS, DAG, JE); analysis of the data (MLC, DAG, DAG, $\mathrm{HCH}$ ); drafting of the manuscript (MLC, GSL, KMS, DAG, HCH, JE); critical revision of the manuscript (MLC, GSL, KMS, DAG, JE, HCH); and approval of final manuscript (MLC, GSL, KMS, DAG, JE, HCH).

Financial/Material Support: None.

Disclosures: None

\section{References}

1. Soar J, Perkins GD, Abbas G, et al. European Resuscitation Council Guidelines for Resuscitation 2010 Section 8. Cardiac arrest in special circumstances: electrolyte abnormalities, poisoning, drowning, accidental hypothermia, hyperthermia, asthma, anaphylaxis, cardiac surgery, trauma, pregnancy, electrocution. Resuscitation. 2010;81: $1400-1433$.

2. Balvers K, Van de Horst M, Graumans M, et al. Hypothermia as a predictor for mortality in trauma patients at admittance to the intensive care unit. J Emerg Trauma Shock. 2016:9:97-102.

3. Brown DJ, Brugger H, Boyd J, Paal P. Accidental hypothermia. N Engl J Med. 2012;367:1930-1938.

4. Danzl DF, Pozos RS, Auerbach PS, et al. Multicenter hypothermia survey. Ann Emerg Med. 1987;16:1042-1055.

5. Giesbrecht GG, Ducharme MB, McGuire JP. Comparison of forced-air patient warming systems for perioperative use. Anesthesiology. 1994;80:671-679.

6. Hultzer MV, Xu X, Marrao C, Bristow G, Chochinov A, Giesbrecht GG. Pre-hospital torso-warming modalities for severe hypothermia: a comparative study using a human model. CJEM. 2005;7:378-386. 
7. Giesbrecht GG, Bristow GK, Uin A, Ready AE, Jones RA. Effectiveness of three field treatments for induced mild (33.0 degrees C) hypothermia. J Appl Physiol. 1987;63: 2375-2379.

8. Harnett RM, O'Brien EM, Sias FR, Pruitt JR. Initial treatment of profound accidental hypothermia. Aviat Space Environ Med. 1980;51:680-687.

9. Giesbrecht GG, Sessler DI, Mekjavic IB, Schroeder M, Bristow GK. Treatment of mild immersion hypothermia by direct body-to-body contact. J Appl Physiol (1985). 1994;76: 2373-2379.

10. Sran BJ, McDonald GK, Steinman AM, Gardiner PF, Giesbrecht GG. Comparison of heat donation through the head or torso on mild hypothermia rewarming. Wilderness Environ Med. 2014;25:4-13.

11. Eyolfson DA, Tikuisis P, Xu X, Weseen G, Giesbrecht GG. Measurement and prediction of peak shivering intensity in humans. Eur J Appl Physiol. 2001;84:100-106.

12. Wyss CR, Brengelmann GL, Johnson JM, Rowell LB, Niederberger M. Control of skin blood flow, sweating, and heart rate: role of skin vs. core temperature. J Appl Physiol. 1974;36:726-733.

13. Giesbrecht GG, Bristow GK. The convective afterdrop component during hypothermic exercise decreases with delayed exercise onset. Aviat Space Environ Med. 1998;69:17-22.

14. Kumar P, McDonald GK, Chitkara R, Steinman AM, Gardiner PF, Giesbrecht GG. Comparison of distal limb warming with fluidotherapy and warm water immersion for mild hypothermia rewarming. Wilderness Environ Med. 2015;26:406-411.

15. Vanggaard L, Eyolfson D, Xu X, Weseen G, Giesbrecht GG. Immersion of distal arms and legs in warm water (AVA rewarming) effectively rewarms mildly hypothermic humans. Aviat Space Environ Med. 1999;70:1081-1088.

16. Bergersen TK, Eriksen M, Walloe L. Effect of local warming on hand and finger artery blood velocities. Am J Physiol. 1995;269:R325-R330.

17. Grahn D, Brock-Utne JG, Watenpaugh DE, Heller HC. Recovery from mild hypothermia can be accelerated by mechanically distending blood vessels in the hand. J Appl Physiol (1985). 1998;85:1643-1648.

18. Grahn DA, Cao VH, Heller HC. Heat extraction through the palm of one hand improves aerobic exercise endurance in a hot environment. $J$ Appl Physiol. 2005;99:972-978.

19. Zafren K, Giesbrecht GG, Danzl DF, et al. Wilderness Medical Society practice guidelines for the out-of-hospital evaluation and treatment of accidental hypothermia: 2014 update. Wilderness Environ Med. 2014;25(suppl 4):S66S85.

20. Watts DD, Roche M, Tricarico R, et al. The utility of traditional prehospital interventions in maintaining thermostasis. Preshosp Emerg Care. 1999;3:115-122.

21. Fildes J, Sheaff C, Barrett J. Very hot intravenous fluid in the treatment of hypothermia. J Trauma. 1993;35:683-686.

22. Jeong SM, Hahm KD, Jeong YB, Yang HS, Choi IC. Warming of intravenous fluids prevents hypothermia during off-pump coronary artery bypass graft surgery. J Cardiothorac Vasc Anesth. 2008;22:67-70.

23. Smith CE, Desai R, Glorioso V, Cooper A, Pinchak AC, Hagen KF. Preventing hypothermia: convective and intravenous fluid warming versus convective warming alone. J Clin Anesth. 1998;10:380-385.

24. Lapostolle F, Sebbah JL, Couvreur J, et al. Risk factors for onset of hypothermia in trauma victims: the HypoTraum study. Crit Care. 2012;16:R142.

25. Duchesne JC, McSwain NE Jr, Cotton BA, et al. Damage control resuscitation: the new face of damage control. J Trauma. 2010;69:976-990.

26. Gentilello LM. Advances in the management of hypothermia. Surg Clin North Am. 1995;75:243-256.

27. Olson DM, Grissom JL, Williamson RA, Bennett SN, Bellows ST, James ML. Interrater reliability of the bedside shivering assessment scale. Am J Crit Care. 2013;22: 70-74.

28. Badjatia N, Strongilis E, Gordon E, et al. Metabolic impact of shivering during therapeutic temperature modulation: the Bedside Shivering Assessment Scale. Stroke. 2008;39:3242-3247.

29. Thomassen O, Faerevik H, Osteras O, et al. Comparison of three different prehospital wrapping methods for preventing hypothermia-a crossover study in humans. Scand J Trauma Resusc Emerg Med. 2011;19:41.

30. Giesbrecht GG. Prehospital treatment of hypothermia. Wilderness Environ Med. 2001;12:24-31.

31. DeClerck MP, Lipman GS, Grahn DA, et al. A chemical heat pack-based method for consistent heating of intravenous fluids. Wilderness Environ Med. 2015;26:412-416.

32. Giesbrecht GG, Schroeder M, Bristow GK. Treatment of mild immersion hypothermia by forced-air warming. Aviat Space Environ Med. 1994;65:803-808.

33. Cahill CJ, Balmi PJ, Tipton MJ. An evaluation of hand immersion for rewarming individuals cooled by immersion in cold water. Aviat Space Environ Med. 1995; 66:418-423.

34. Giesbrecht GG, Lockhart TL, Bristow GK, Steinman AM. Thermal effects of dorsal head immersion in cold water on nonshivering humans. J Appl Physiol. 2005;99: 1958-1964.

35. Folkow B, Neil E, eds. Circulation. New York, NY: Oxford University Press; 1971:593.

36. Deakin CD, Morrison LJ, Morley PT, et al. Part 8: advanced life support: 2010 International Consensus on Cardiopulmonary Resuscitation and Emergency Cardiovascular Care Science with Treatment Recommendations. Resuscitation. 2010;81(suppl 1):e93-e174.

37. Joslin J, Fisher A, Wojcik S, Cooney DR. A prospective evaluation of the contribution of ambient temperatures and transport times on infrared thermometry readings of intravenous fluids utilized in EMS patients. Int J Emerg Med. 2014;7:47.

38. Guyton AC, Hall JE. Textbook of Medical Physiology. 11th ed. Philadelphia, PA: Elsevier, Inc; 2006889-901. 
39. Diaz M, Becker DE. Thermoregulation: physiological and clinical considerations during sedation and general anesthesia. Anesth Prog. 2010;57:25-33.

40. Asami T, Hori T, Kiyohara T, Nakashima T. Convergence of thermal signals on the reticulospinal neurons in the midbrain, pons and medulla oblongata. Brain Res Bull. 1988;20:581-596.

41. Giesbrecht GG, Bristow GK. Recent advances in hypothermia research. Ann N Y Acad Sci. 1997;813:663-675.
42. Giesbrecht GG, Bristow GK. A second postcooling afterdrop: more evidence for a convective mechanism. J Appl Physiol (1985). 1992;73:1253-1258.

43. Daanen HA, Van de Linde FJ. Comparison of four noninvasive rewarming methods for mild hypothermia. Aviat Space Environ Med. 1992;63:1070-1076.

44. Stocks JM, Taylor NAS, Tipton MJ, Greenleaf JE. Human physiological responses to cold exposure. Aviat Space Environ Med. 2004;75:444-457. 